\title{
Right ventricular pseudoaneurysm in a young adult following right heart catheterization: a rare case report and review of the literature
}

\author{
Habib Ahmad Esmat ${ }^{1,2^{*}}$ (D, Naim Ceylan ${ }^{2}$, Emre Demir ${ }^{3}$ and Akın Çinkooğlu ${ }^{2}$
}

\begin{abstract}
Background: Right ventricular pseudoaneurysm is an extremely rare finding than left ventricular pseudoaneurysm, associated with high mortality. The diagnosis of right ventricle pseudoaneurysm is often challenging because of its rarity and lack of typical clinical features. However, advanced cardiac imaging techniques including CT angiogram and MRI can help a timely diagnosis to avoid a fatal outcome.

Case presentation: The authors present the imaging findings of a right ventricular pseudoaneurysm in a 33-yearold male, presented with dyspnea and chest pain after exertion for 2 weeks. The gated $C T$ and cardiac MRI showed a small outpouching from the right ventricle apex into the pericardial space, consistent with a pseudoaneurysm. He underwent cardiac surgery and pseudoaneurysm resection with a favorable outcome.

Conclusion: Right ventricular pseudoaneurysm is a very rare complication following right heart catheterization and a potentially life-threatening condition that requires prompt diagnosis and management. Though the lack of its typical clinical presentation is often a diagnostic challenge, advanced cardiac imaging techniques including CT angiogram and MRI may help a timely diagnosis to avoid a fatal outcome.
\end{abstract}

Keywords: Right ventricle, Pseudoaneurysm, Catheterization, Case report

\section{Background}

Ventricular pseudoaneurysm is a contained rupture of the ventricular wall that may occur due to cardiac trauma, congenital heart surgery, endomyocardial biopsy, pacemaker placement, central venous or pulmonary artery catheterization, infections, and postmyocardial infarction $[1,2]$. A cardiac pseudoaneurysm differs from a true aneurysm because its wall does not contain myocardial tissues and connects to the ventricle by a small neck. Thus, ventricular pseudoaneurysm is prone to fatal rapture and subsequent high mortality $[1$,

\footnotetext{
* Correspondence: habib.smt@gmail.com

'Department of Radiology, Kabul University of Medical Sciences, Kabul, Afghanistan

2Department of Radiology, Ege Universitesi Tip Fakultesi, Izmir, Turkey Full list of author information is available at the end of the article
}

3]. Although left ventricular pseudoaneurysm is uncommon, right ventricular pseudoaneurysm is extremely rare $[2,3]$. Transthoracic echocardiogram, cardiac MRI, and CT angiography can help diagnosis and management [4]. Surgical repair or percutaneous closure is required to reduce the risk of rupture and the potential for thromboembolism, especially if acute or associated with symptoms $[4,5]$. We present here the imaging findings of a post-cardiac catheterization right ventricular pseudoaneurysm in a 33-year-old male.

\section{Case presentation}

A 33-year-old male was referred to our hospital from a private center, complaining of dyspnea and chest pain after exertion for 2 weeks. On physical exam, he had normal vital signs and other findings were unremarkable. 
The coronary angiogram had no evidence for coronary artery disease except for some fistulas between left coronary artery branches along the interventricular septum and Swan-Ganz catheterization showed increased right ventricular end-diastolic pressure, equal to the left. In the past, the patient was hospitalized due to chest pain in the same private hospital and examined with coronary angiography three times; the last time was in 2014, which had negative results for coronary artery disease. On transthoracic echocardiogram, the right ventricle and right atrium were dilated with moderate to severe tricuspid regurgitation, but the acoustic window was poor for image quality to obtain other findings. For further evaluation, the patient was referred to thoracic radiology for imaging studies. On pre- and post-contrast gated CT angiogram, a small $20 \mathrm{~mm} \times 12 \mathrm{~mm}$ outpouching from the right ventricle apex into the pericardial space, connected through a small neck to the ventricle was observed, compatible with right ventricular pseudoaneurysm (Fig. 1a-c). Minimal pericardial effusion was seen adjacent to the right ventricle. The 3D volume rendering CT image confirmed the diagnosis (Fig. 2). The right ventricle and right atrium were moderately dilated and a small defect of approximately $3 \mathrm{~mm}$ was observed in the upper part of the interatrial septum,

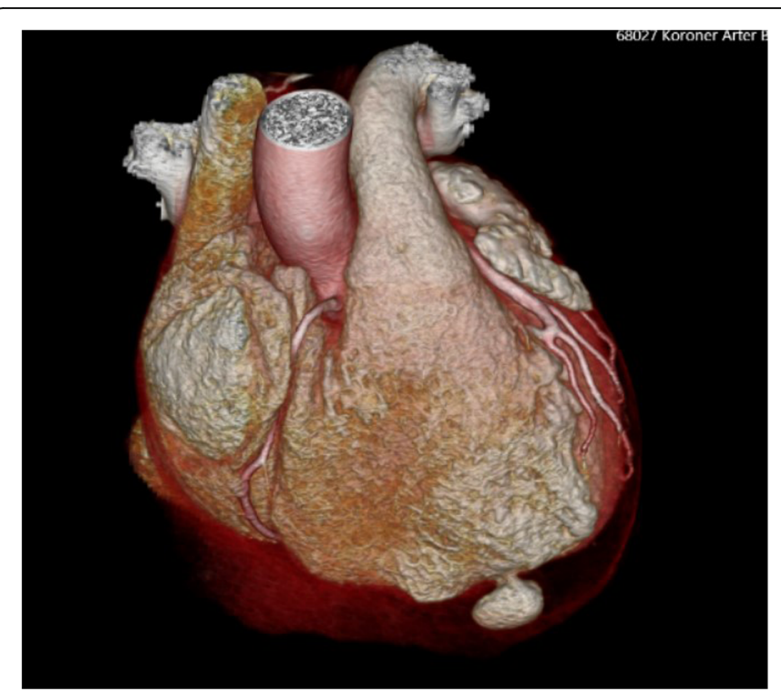

Fig. 2 The 3D volume rendering CT image shows a small outpouching from the right ventricle apex into the pericardial space, connected through a small neck to the ventricle
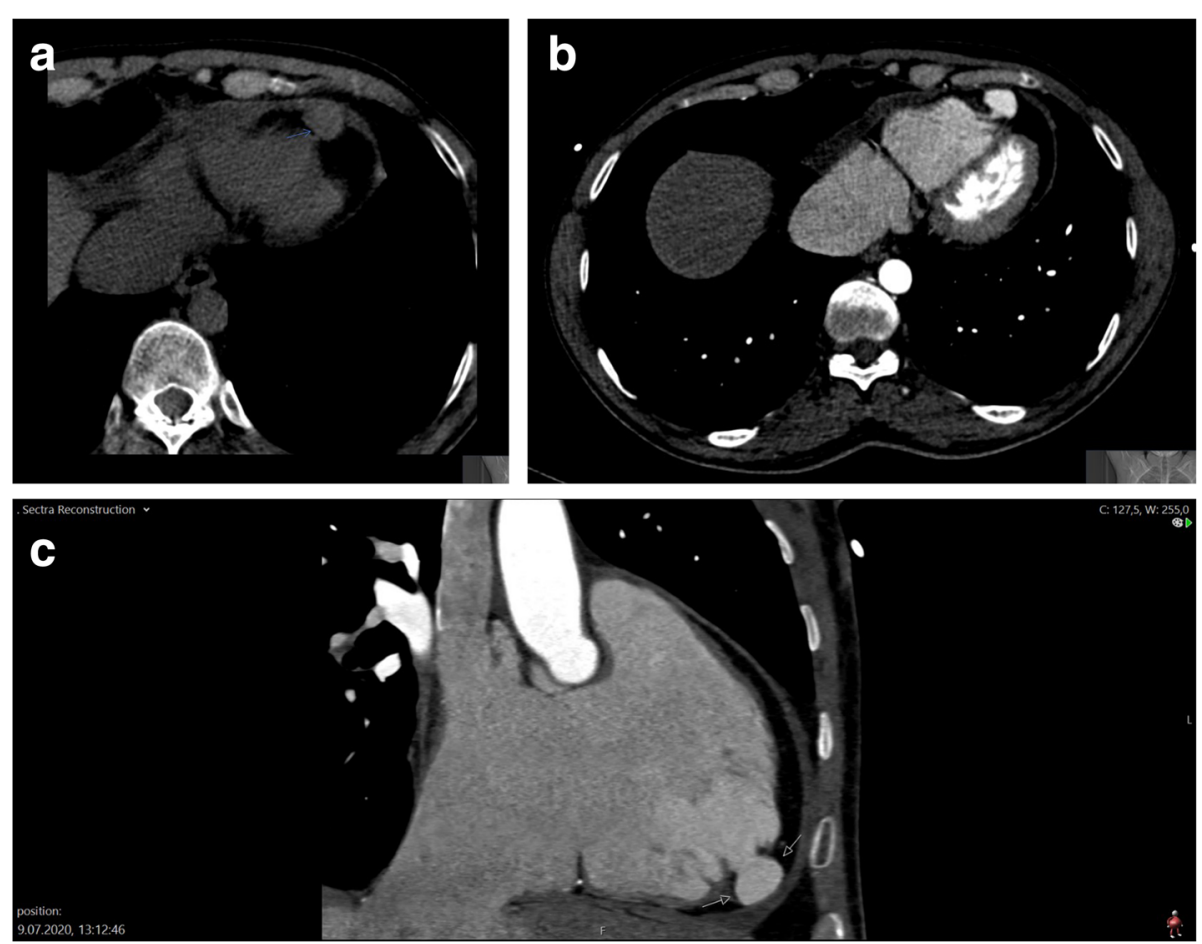

Fig. 1 a Pre-contrast gated CT angiogram shows a small outpouching from the right ventricle apex into the pericardial space, connected through a small neck to the ventricle. b Post-contrast gated CT angiogram shows a small outpouching from the right ventricle apex into the pericardial space, connected through a small neck to the ventricle. c Reconstructed gated CT image shows a small outpouching from the right ventricle apex into the pericardial space, connected through a small neck to the ventricle with minimal pericardial effusion adjacent to the right ventricle 


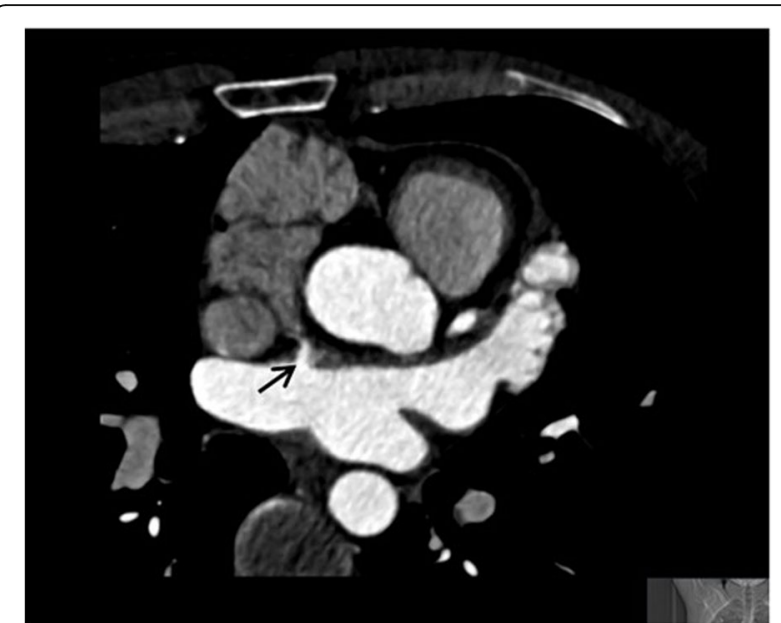

Fig. 3 Gated CT angiogram shows a small defect in the upper part of the interatrial septum

allowing the passage of contrast media through this area towards the upper part of the right atrium, consistent with atrial septal defect (Fig. 3). For differential diagnosis of suspected constrictive pericarditis, the gated-MRI was obtained that showed the same findings as observed on CT images (Fig. 4). The patient underwent open thoracic cardiac surgery by a qualified cardiac surgery team in the cardiac surgery unit. The pseudoaneurysm was resected and no changes or complications occurred during or after the operation. He had good condition during the hospital stay and was discharged from the hospital with a favorable outcome.

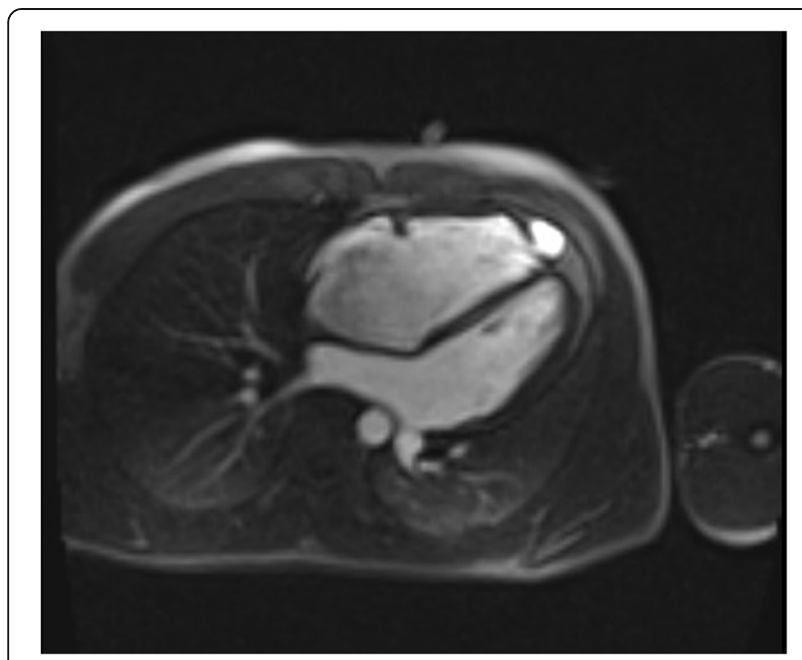

Fig. 4 Post-contrast four-chamber gated-MRI shows a small outpouching from the right ventricle apex into the pericardial space, connected through a small neck to the ventricle

\section{Discussion}

A pseudoaneurysm results from a rupture of the ventricular wall with the containment of the resultant hematoma by pericardium or extracardiac structures [6]. It may occur after cardiac trauma, congenital heart surgery, endomyocardial biopsy, pacemaker placement, infections, post-myocardial infarction, and central venous or pulmonary artery catheterization [2]. For decades, Swan-Ganz catheter is used for measuring cardiac filling pressure and the incidence of its known complications is less than $1 \%$, which includes the rapture of the pulmonary artery, knotting, and right ventricular free wall perforation [2, 7]. Our case describes a right ventricular pseudoaneurysm after right heart catheterization in a patient with right heart failure in the setting of an atrial septal defect. Initial imaging demonstrated no clear evidence of pseudoaneurysm or compressive effects on the right ventricle and its determination was made upon further evaluation with cardiac CT angiography, which has high spatial resolution than transthoracic echocardiography.

Most of the patients with cardiac pseudoaneurysm have no typical clinical presentation and some are asymptomatic [8]. Symptoms may include mediastinal mass effect, thromboembolism, arrhythmia, chest pain, and rupture. As the pseudoaneurysm slowly increases in size, the compressive effects get worse $[3,9]$. Our patient presented with chest pain and dyspnea after exertion that could be due to pulmonary hypertension resulting from the preexisting atrial septal defect.

Multiple imaging modalities including echocardiography, CT, and MRI can be used for the diagnosis of ventricular pseudoaneurysm [4]. Echocardiography is the first-line method for diagnosis because of its easy availability and routine usage but has low sensitivity [3]. However, in our case echocardiography failed to detect RV pseudoaneurysm. An ECG-gated CT scan can provide more detailed anatomic information, size, neck, and origin of pseudoaneurysm as well as the myocardial enhancement pattern [10]. Cardiac MRI can be used to obtain functional and anatomic information [6]. Both CT and MRI are non-invasive with a high special resolution, which improve the visualization of segments that may be difficult to see on echocardiography [3]. In our case, the CT and MRI provided vital information for an accurate diagnosis. The right ventricular pseudoaneurysm can be successfully managed with conservative treatment. However, in high-risk patients with tamponade, severe pulmonary hypertension, and hemodynamic deterioration the surgical intervention or percutaneous closure is the mainstay of treatment $[1,10]$. Although this is a rare and surgically proven case, lack of longtime follow -up may be the only limitation for this case report. 


\section{Conclusion}

Right ventricular pseudoaneurysm is a very rare complication following right heart catheterization and a potentially life-threatening condition that requires prompt diagnosis and management. Though the lack of its typical clinical presentation is often a diagnostic challenge, advanced cardiac imaging techniques including CT angiogram and MRI can help a timely diagnosis to avoid a fatal outcome.

\section{Abbreviations}

CT: Computed tomography; MRI: Magnetic resonance imaging

\section{Acknowledgements}

Not applicable.

\section{Authors' contributions}

Concept - NC; Design - HAE; Supervision - NC; Resources and data collection - ED; Literature search - HAE; Writing manuscript - HAE; Critical review - AC. All authors have read and approved the final manuscript.

\section{Funding}

We declare that our work is not funded by any institution, organ, or government and we have no financial support.

\section{Availability of data and materials}

The data used during the current study are available from the corresponding author on reasonable request.

\section{Ethics approval and consent to participate}

The manuscript has got an ethical review exemption from the Ethical Review Committee (ERC) of our hospital as case reports are exempted from review according to our institutional ethical review committee's policy.

\section{Consent for publication}

Written informed consent was obtained from the patient for publication of this case report and any accompanying images. A copy of the written consent is available for review by the editor of this journal.

\section{Competing interests}

The authors have no potential conflicts of interest to disclose regarding the publication of this paper.

\section{Author details}

'Department of Radiology, Kabul University of Medical Sciences, Kabul, Afghanistan. ${ }^{2}$ Department of Radiology, Ege Universitesi Tip Fakultesi, Izmir, Turkey. ${ }^{3}$ Department of Cardiology, Ege Universitesi Tip Fakultesi, Izmir, Turkey.

Received: 1 December 2020 Accepted: 10 January 2021

Published online: 20 January 2021

\section{References}

1. Lippmann M, Wiley M, Freeman J, Abicht T, Nath J (2019) Percutaneous closure of a traumatic right ventricular pseudoaneurysm: a novel interventional approach. CASE (Philadelphia, Pa.) 3(2):60-62. https://doi.org/ 10.1016/j.case.2018.11.005

2. Ulucam M (2012) Story of a little right ventricular pseudoaneurysm. Open J Med Imaging 2(4):162-166. https://doi.org/10.4236/ojmi.2012.24026

3. Gaddipati VC, Martin Al, Valenzuela MO, Mahmud A, Patel AA (2017) An incidentally detected right ventricular pseudoaneurysm. Case Rep Cardiol 2017:4352474. https://doi.org/10.1155/2017/4352474

4. Ansari-Gilani K, Sabik EL, Sareyyupoglu B, Gilkeson RC (2019) Multimodality imaging of right ventricular pseudoaneurysm caused by blunt chest trauma. J Am Coll Cardiol Case Rep 1(3):287-290. https://doi.org/10.1016/j.jaccas. 2019.08.006

5. Hulten EA, Blankstein R (2012) Pseudoaneurysms of the heart. Circulation 125(15):1920-1925. https://doi.org/10.1161/CIRCULATIONAHA.111.043984
6. Sreeram N, Sutherland GR, McGhie J (1990) Pseudoaneurysm of the right ventricular outflow tract: diagnosis by colour flow mapping. Br Heart J 63(2): 129-131. https://doi.org/10.1136/hrt.63.2.129

7. Bossert T, Gummert JF, Bittner HB, Barten M, Walther T, Falk V, Mohr FW (2006) Swan-Ganz catheter-induced severe complications in cardiac surgery: right ventricular perforation, knotting, and rupture of a pulmonary artery. J Cardiac Surg 21(3):292-295. https://doi.org/10.1111/j.1540-8191.2006.00235.x

8. Yeo TC, Malouf JF, Oh JK, Seward JB (1998) Clinical profile and outcome in 52 patients with cardiac pseudoaneurysm. Ann Intern Med 128(4):299-305. https://doi.org/10.7326/0003-4819-128-4-199802150-00010

9. Calabrò R, Santoro G, Pisacane C, Pacileo G, Russo MG, Vosa C (1999) Repeat syncopal attacks due to postsurgical right ventricular pseudoaneurysm. Ann Thorac Surg 68(1):252-254. https://doi.org/10.1016/s0003-4975(99)00497-x

10. Kang T, Kang MJ, Kim JH (2014) Spontaneous obliteration of right ventricular pseudoaneurysm after blunt chest trauma: diagnosis and followup with multidetector CT. Korean J Radiol 15(3):330-333. https://doi.org/10. 3348/kjr.2014.15.3.330

\section{Publisher's Note}

Springer Nature remains neutral with regard to jurisdictional claims in published maps and institutional affiliations.

\section{Submit your manuscript to a SpringerOpen ${ }^{\circ}$ journal and benefit from:}

- Convenient online submission

- Rigorous peer review

- Open access: articles freely available online

- High visibility within the field

- Retaining the copyright to your article

Submit your next manuscript at $\boldsymbol{\nabla}$ springeropen.com 